\title{
Breeding value of selected blackcurrant (Ribes nigrum L.) genotypes for early-age fruit yield and its quality
}

\author{
Agnieszka Masny $\cdot$ Stanisław Pluta $\cdot$ Lukasz Seliga
}

Received: 11 January 2018/Accepted: 27 April 2018/Published online: 5 May 2018

(C) The Author(s) 2018

\begin{abstract}
The study was conducted in the years from 2011 to 2013 at the Research Institute of Horticulture in Skierniewice, Poland. The aim of the research was to assess the breeding value, based on the effects of general and specific combining abilities (GCA and SCA), of 15 parental genotypes of blackcurrant in terms of fruit yield and quality. The plant material consisted of $F_{1}$ generation seedlings obtained by crossing, in a factorial mating design of twelve maternal ('Bona', 'Big Ben', 'Chereshnieva', Kupoliniai', 'Gofert', 'Tines', 'Sofievskaia', 'Tihope', 'Ores', 'Ruben', 'Titania' and D13B/11) and three paternal cultivars ('Ceres', 'Foxendown' and 'Saniuta'). It was found that the cultivars 'Ruben', 'Big Ben', 'Gofert' and D13B/11 had significant positive effects of GCA on fruit yield at least in two consecutive years. 'Ruben', 'Saniuta' and D13B/11 had positive GCA effects on fruit weight. For 'Chereshnieva', 'Gofert', 'Tines', 'Sofievskaia', 'Tihope', 'Titania', 'Ceres' and Saniuta' positive GCA effects were estimated for soluble solids content, whereas 'Ruben', 'Ceres', 'Gofert' and 'Ores' had positive GCA effects on the ascorbic acid content in fruit. This indicated a high breeding value of these parental genotypes in terms of the evaluated traits. The
\end{abstract}

A. Masny $(\bowtie) \cdot S$. Pluta $\cdot$ Ł. Seliga

Department of Horticultural Crop Breeding, Research Institute of Horticulture, Konstytucji 3 Maja 1/3,

96-100 Skierniewice, Poland

e-mail: Agnieszka.Masny@inhort.pl significantly positive values of SCA, estimated for the crossing combinations: 'Big Ben' $\times$ 'Saniuta', 'Ruben' $\times$ 'Foxendown', 'Titania' $\times$ 'Ceres', 'Kupoliniai' $\times$ 'Saniuta', 'Gofert' $\times$ 'Foxendown', 'Gofert' $\times$ 'Saniuta', 'Tines' $\times$ 'Ceres' and 'Tihope' $\times$ 'Foxendown' for at least two traits describing fruit yield and quality, were evidence of the interaction of both these parental genotypes in the creation of new dessert-type cultivars of blackcurrant.

Keywords Fruit weight - Extract - Ascorbic acid content $\cdot$ Combining ability $\cdot$ GCA $\cdot$ SCA

\section{Introduction}

Blackcurrant (Ribes nigrum L.) fruits are valued for their high nutritional and dietary qualities. They contain large amounts of vitamins, especially C (Vagiri 2012; Hummer and Barney 2002), and minerals such as potassium, phosphorus, manganese, zinc, chromium and boron (Blackcurrant Foundation 2017), as well as numerous antioxidant compounds, such as phenols and anthocyanins-mainly cyanidin and delphinidin (Bordonaba and Terry 2008; Brennan and Graham 2009). The level of anthocyanin compounds in blackcurrant fruit largely depends on the genotype, but can be modified under different climatic and environmental conditions (Hancock et al. 2007). In addition to the bioactive compounds, the high quality 
of the fruit is determined by the soluble solids content, and the ratio between the amount of sugars and acids (Kaldmäe et al. 2013). These compounds determine the quality and taste of blackcurrant berries (Bordonaba and Terry 2008), and are of particular importance in their production for the fresh fruit market.

At present, breeding of new blackcurrant varieties is conducted in about 15 breeding centres around the world, most of which are located in Europe, mainly in Scotland, Denmark, Sweden, Norway, Finland, in the Baltic States (Lithuania, Latvia and Estonia), in Ukraine and Poland (Vagiri 2012). The main objectives of modern blackcurrant breeding programmes are: resistance/tolerance to pests and diseases, such as the gall mite (Cecidophyopsis ribis Westw.), a vector for the blackcurrant reversion nepovirus, mildew caused by Podosphaera mors-uvae (Schwein.) U. Braun \& S. Takam., septoria leaf spot caused by Mycosphaerella ribis (Sacc.) Lindau, anthracnose caused by Drepanopeziza ribis (Kleb.) Höhn. and rust caused by Cronartium ribicola J.C. Fisch., and also strong plant growth, long berry clusters, large berries, increased fruit firmness, high productivity and suitability for mechanical harvesting. Increasingly, more importance is being placed on high concentration of bioactive compounds and soluble solids, as well as sensory parameters, such as flavour intensity, colour, sourness, mouth feel and aroma (Brennan 2008; Vagiri 2012). Pluta et al. (2008a, b) identified promising high quality blackcurrant genotypes suitable for the development of new fresh fruit, which differed phenotypically and genetically from genotypes suited for processing. They found that cultivars 'Big Ben' and 'Storklass' were the most suitable parental forms for breeding of new genotypes with high quality fruit due to their stable and reasonable general combining ability effects for the fresh fruit traits.

To achieve rapid progress in conventional blackcurrant breeding, it is important to select appropriate parental forms for cross-breeding programmes. Additionally, knowledge of the breeding value, as well as the fundamental knowledge of inheritance and the genetic determination of quantitative traits at the population level, increase the probability of achieving the desired goal quicker (Muszyński 2000). The breeding value of a parental forms is determined primarily on the basis of the effects of the general (GCA) and specific (SCA) combining abilities of that parental forms (Pluta et al. 2014; Żurawicz et al. 2006). The GCA of a parent for the trait under consideration determines its ability to pass on the average level of this trait to its progeny (Baker 1978; Vieira et al. 2009), and the GCA effect is a measure of the additive effect of the parental genes on this trait (Griffing 1956a, b). The use of parental forms with significantly positive GCA effects for a given trait markedly increases the probability of obtaining hybrid progeny with the desired values of this trait (Bestfleisch et al. 2014; Masny et al. 2016a, b; Pluta et al. 2014). SCA refers to a pair of parental forms and is the interaction of both parents in the genetic determination of the trait under consideration, revealed in their progeny (Griffing 1956a, b; Baker 1978). Thus, the SCA effect is the result of non-additive action of genes (domination and epistasis). It represents the difference between the mean value of the trait revealed in progeny (full siblings of two parental forms) and the sum of GCA effects for these parental forms (Bestfleisch et al. 2014). The GCA and SCA effects of parents evaluated in factorial or diallel mating designs are measures of their breeding value for the traits under consideration, i.e. the usefulness of the parents in breeding programmes focused on improving these traits in new cultivars (Baker 1978; Bestfleisch et al. 2014; Pluta et al. 2014). The probability of success in selecting the most efficient parents in a breeding programme will be further enhanced if the SCA of particular parental combinations is also considered when only genetic variation exists in a breeding gene pool. The quotient of the mean square deviations for GCA and SCA $\left(\mathrm{S}_{\mathrm{GCA}}^{2} / \mathrm{S}_{\mathrm{SCA}}^{2}\right)$ provides for the determination of which genetic effects (additive or nonadditive) have a predominant share in determining a given trait in the tested progeny (Fort and Shaw 2000).

Genetic knowledge on the inheritance of quantitative traits in blackcurrant is limited due to the costly and labour-intensive research that requires extended periods of data collection. As in other fruit crops, these include heritability, variance components and correlations, as well as the combining ability of potential parental genotypes such as cultivars, clones, selections and germplasm accessions (Yao and Mehlenbacher 2000; Pluta et al. 2014). Earlier studies on the inheritance of selected traits in blackcurrant showed that the phenotypic performance of morphological traits such as bush size, length of one-year-old shoots, 
plant growth habit, plant vigour, as well as yield per bush and uniformity of berry ripening were determined mainly by non-additive effects as a result of dominance or epistasis (Żurawicz et al. 1996). Some traits, such as flowering time and flower susceptibility to spring frosts, were determined equally by additive and non-additive effects. Variation due to additive genetic effects was greater than for non-additive effects for the following traits: resistance to powdery mildew (Ravkin 1981), white pine blister rust and leaf spot, bush defoliation and the length of strigs (Żurawicz et al. 1996).

The aim of our study was to determine the breeding value of 15 blackcurrant genotypes in terms of GCA and SCA effects for traits describing fruit yield and its quality using a factorial mating design. The importance and use of the findings in practical breeding of modern blackcurrant cultivars adapted to Polish and European agro-ecosystems, cultivation practices, and market requirements are also discussed.

\section{Materials and methods}

Location, plant material and experimental conditions

The experiment was conducted in the Experimental Orchard in Dąbrowice, belonging to the Research Institute of Horticulture in Skierniewice (central Poland, lat. $51.959^{\circ} \mathrm{N}$, long. $20.139^{\circ} \mathrm{E}$ ) in 2011-2013. Seedlings of $F_{1}$ generation of 36 hybrid families were obtained from crosses in a factorial mating design (Garretsen and Keuls 1978; Nduwumuremyi et al. 2013) made between 12 maternal ('Bona', 'Big Ben', 'Chereshnieva', 'Kupoliniai', 'Gofert', 'Tines', 'Sofievskaia', 'Tihope', 'Ores', 'Ruben', 'Titania' and D13B/11) and three paternal ('Ceres', 'Foxendown' and 'Saniuta') cultivars. Each maternal cultivar was crossed with each paternal form. A brief description of the crossed genotypes is given in Table 1.

The crosses were performed between March 18 and 29, 2008 in the high plastic tunnel to avoid spring frost damage to flower buds and flowers. In October 2008, the seeds were sown into $3.3 \mathrm{~L}$ pots filled with a $3: 1$ mixture of peat substrate and sand, and placed in a refrigerator for stratification. At the beginning of
January 2009, the pots were moved to a heated greenhouse $\left(20^{\circ} \mathrm{C} / 16^{\circ} \mathrm{C}\right.$ day/night temperature, $16 \mathrm{~h}$ photoperiod). Emerging seedlings were transplanted into $0.25 \mathrm{~L}$ pots filled with a 3:1 mixture of peat substrate and sand, and grown from mid-January until the end of May 2009. To set up a field experiment, a total of 2160 seedlings were used. The seedlings were randomly selected from a larger population of hybrids belonging to 36 families. The experiment was established in the spring of 2009, in a randomized block design, with four replications of 15 plants (spaced at $0.5 \times 2.8 \mathrm{~m}$ ) per plot. The management of seedlings in the experiment followed the recommendations for commercial blackcurrant plantations in Poland.

\section{Evaluated traits}

In 2011-2013, all seedlings were evaluated individually for the following traits: fruit yield (kg/plot), mean weight of 100 berries (g) selected randomly at harvest, soluble solids and ascorbic acid content. Quality traits (soluble solids and ascorbic acid) were determined based on a sample consisting of 100 berries selected randomly from each experimental plot. The harvested berries, after washing and de-stalking, were packed into polyethylene bags and placed in a freezer at $-20{ }^{\circ} \mathrm{C}$. After 3 months, the berries were thawed and homogenized. The homogenate was pressed and the juice was used for the determination of soluble solids content with a Rudolph J-157 refractometer (Rudolph Research Analytical, Hackettstown, USA) and ascorbic acid content with a Merck RQ-Easy reflectometer and test strips (Merck KGaA, Darmstadt, Germany).

\section{Statistical analysis}

A two-stage analysis of the plot data obtained during the three-year experiment was performed for all the evaluated traits (Garretsen and Keuls 1978; Möhring and Piepho 2009). Data were analyzed separately for each year as well as for the mean of the three consecutive years. In the first stage, the SAS PROC MIXED procedure (SAS Institute Inc., Cary, NC, USA 2000) was used to perform the analysis of variance (ANOVA) of the plot-means data based on a mixed ANOVA model for the randomized complete block design, assuming the hybrid families to be a fixed factor, while the blocks were considered to be a random factor (Möhring and Piepho 2009). After 


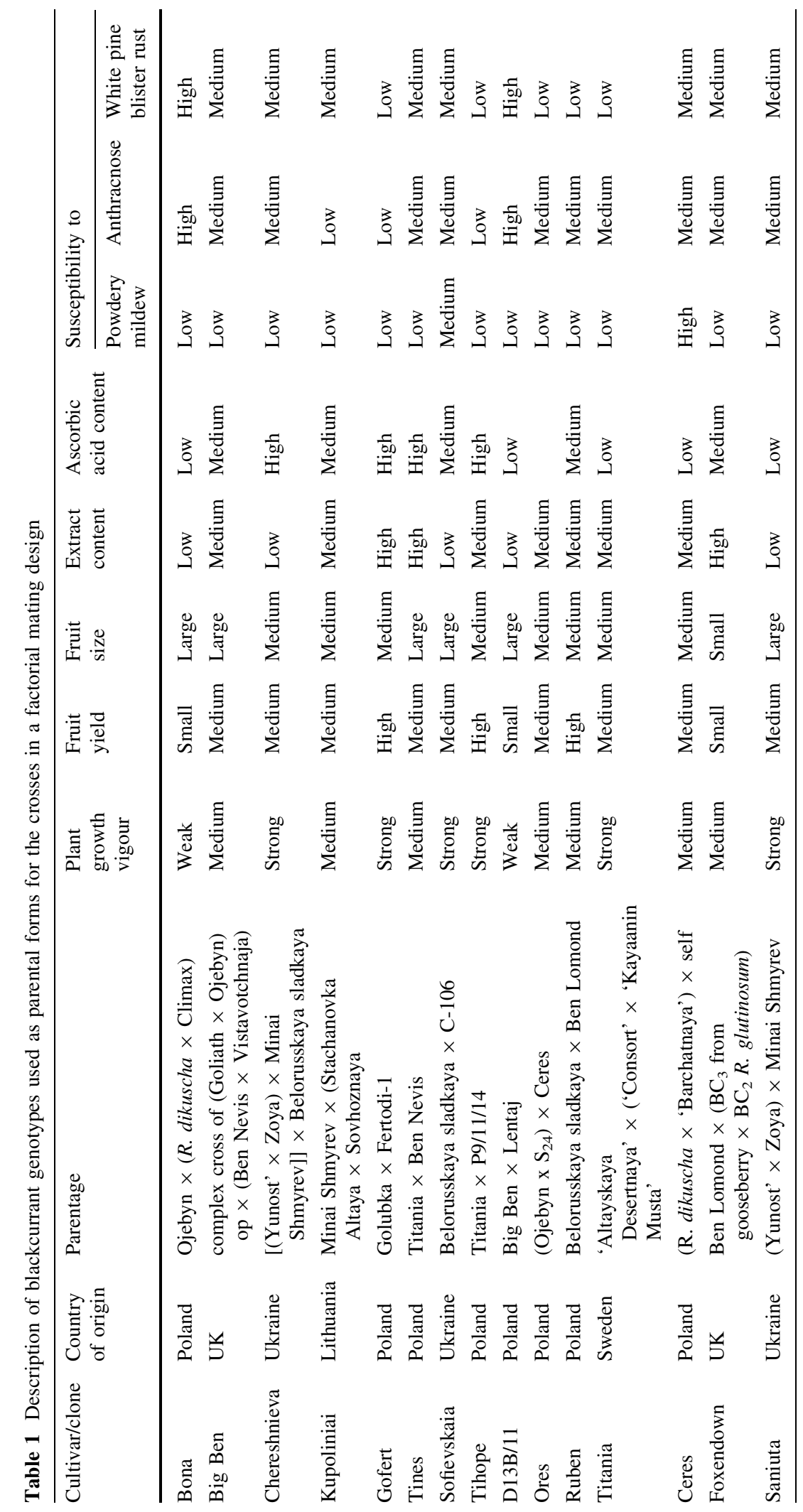


finding significant variation for a given trait among the hybrid families, both comparisons of the hybridfamily means, calculated across the replicates, with the general mean and the second stage of the two-stage analysis were performed. The latter analysis involved performing a fixed-model-based factorial analysis of variance of the family means, and using error mean square from the first stage ANOVA, together with estimating GCA and SCA effects as outlined by Nduwumuremyi et al. (2013) for NC II complete mating design with parents treated as a fixed factor. This factorial analysis was conducted using the SAS PROC GLM procedure (SAS Institute Inc., Cary, NC, USA 2000). A detailed analysis of the significance of the GCA and SCA effects was made using a simultaneous test based on the Bonferroni procedure (Garretsen and Keuls 1978).

\section{Results and discussion}

Phenotypic analysis of hybrid families

The study showed significant differences among the evaluated families of blackcurrant hybrids in terms of fruit yield and selected traits of fruit quality.

\section{Fruit yield}

In 2011 , the fruit yield was very low $(0.28 \mathrm{~kg} / \mathrm{plot}$, on average) due to the young age of the seedlings, and some of the plants did not produce any fruit at all (Table 2). Hybrids of six families yielded significantly $(P<0.05)$ higher, compared with the average yield (so-called general mean) obtained from the bushes of all the hybrid families under evaluation. The highest yield of $0.53 \mathrm{~kg}$ per plot was produced by the hybrids belonging to the families: 'Gofert' $\times$ 'Saniuta' and 'Ruben' $\times$ 'Foxendown'. As expected, due to plant establishment and growth, in the following year (2012), the tested hybrids produced higher yield than in 2011. Hybrids of seven families produced yield more than $1 \mathrm{~kg}$ higher (per plot) than the general mean of fruit yield for all 2160 hybrids. Those families were: 'Ruben' $\times$ 'Foxendown', 'Big Ben' $\times$ 'Ceres', 'Kupoliniai' $\times$ 'Foxendown', 'Big Ben' $\times$ 'Foxendown', D13B/11 × 'Ceres', 'Ruben' $\times$ 'Saniuta' and 'Big Ben' $\times$ 'Saniuta'. In the case of the last family, the yield obtained from the hybrids was $3.8 \mathrm{~kg} / \mathrm{plot}$ greater than the mean fruit yield obtained from all the seedlings. The lowest yield was produced by hybrids of two families: 'Tines' $\times$ 'Ceres' and 'Sofievskaia' × 'Ceres'. In 2013, yield obtained from all the seedlings under evaluation was more than twice as high as in 2012. In this group, hybrids belonging to five families ('Big Ben' $x$ 'Saniuta', 'Ruben' $x$ ' Ceres', 'Ruben' $x$ 'Saniuta', 'Ruben' $\times$ 'Foxendown', 'Chereshnieva' $\times$ 'Foxendown') produced yields at least $2.5 \mathrm{~kg}$ (per plot) higher than the mean yield for all the seedlings. The variation in fruit yield obtained from the hybrids of the different families, especially in 2012 and 2013, allows the conclusion that this trait is modified to a large extent by environmental conditions. This is confirmed by the statistically $(P<0.01)$ proven the high value of the genotypes $\times$ years interaction $(\mathrm{G} \times \mathrm{Y}$; Table 4$)$. In spite of that, fruit yields for most of the evaluated hybrids were stable across 2012-2013, which was confirmed by the lack of a significant $\mathrm{G} \times \mathrm{Y}$ interaction for the individual hybrid families (Table 2). The genotypes for which a significant $\mathrm{G} \times \mathrm{Y}$ interaction was estimated, that might indicate low yield stability in changing weather conditions, were hybrids obtained from the crossing of the cultivars 'Chereshnieva' $\times$ 'Foxendown' and 'Kupoliniai' $\times$ 'Ceres'. Simultaneously, it was observed a big difference in fruit yield values of hybrids of both families across 2011-2013.

\section{Fruit weight}

The mean weight of 100 berries determined for the blackcurrant hybrids under evaluation did not vary much across the 3 years of the study (Table 2). In 2011, only hybrids derived by crossing D13B/11 and 'Foxendown' produced fruit with a significantly $(P<0.01)$ higher weight than the mean fruit weight for all 2160 seedlings. In 2012, the largest berries were produced by the hybrids of the families 'Big Ben' $\times$ 'Saniuta' and D13B/11 $\times$ 'Saniuta', while the smallest were those of the seedlings from the families 'Gofert' $\times$ 'Foxendown' and 'Tihope' $\times$ 'Foxendown'. In 2013, like in 2012, the largest berries were produced by the hybrids 'Big Ben' $\times$ 'Saniuta' and D13B/11 × 'Saniuta', and also 'Sofievskaia' $\times$ 'Saniuta' and 'Ruben' $\times$ 'Saniuta'. Earlier phenotypic observations of numerous cultivars of blackcurrant, conducted by Pluta et al. 


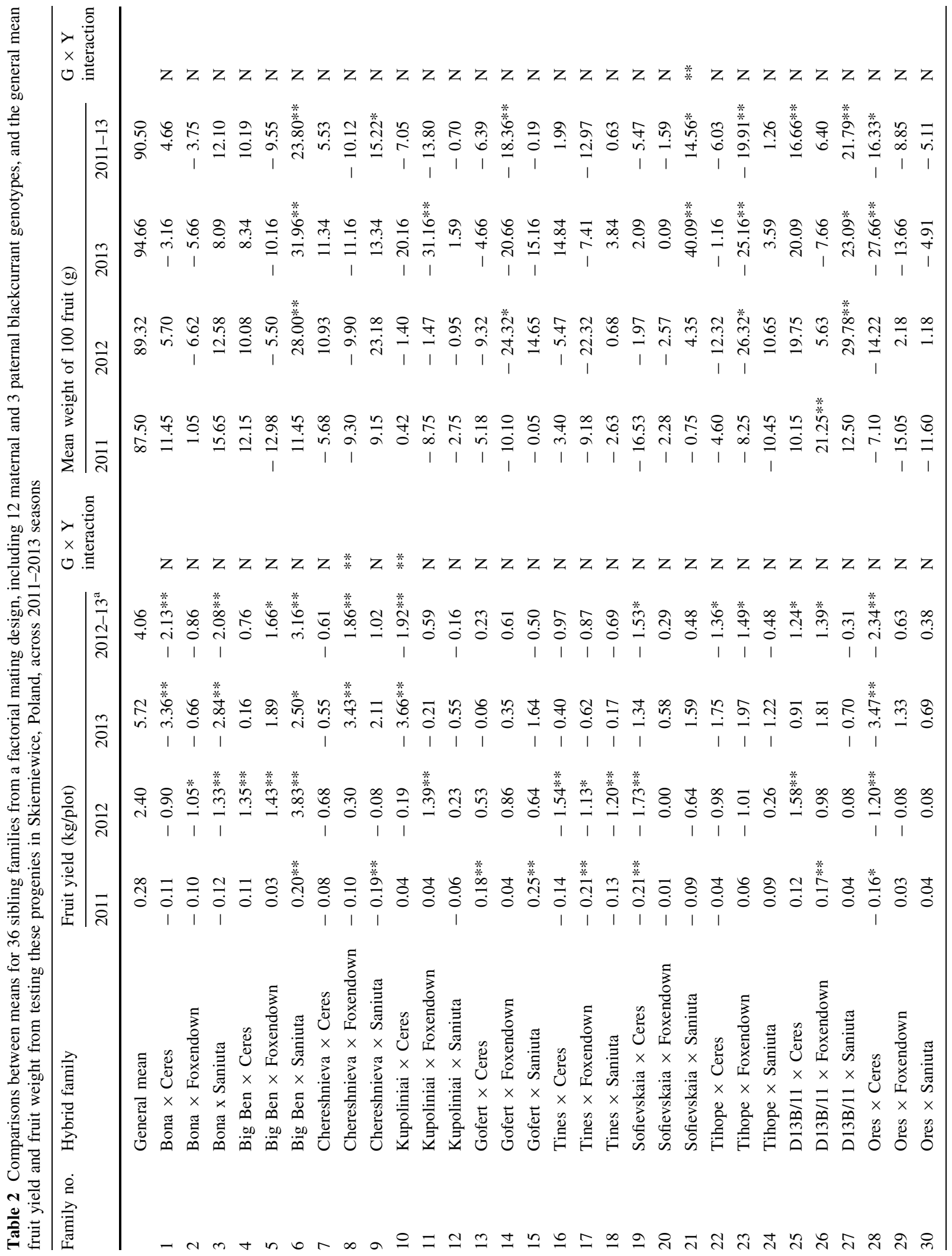




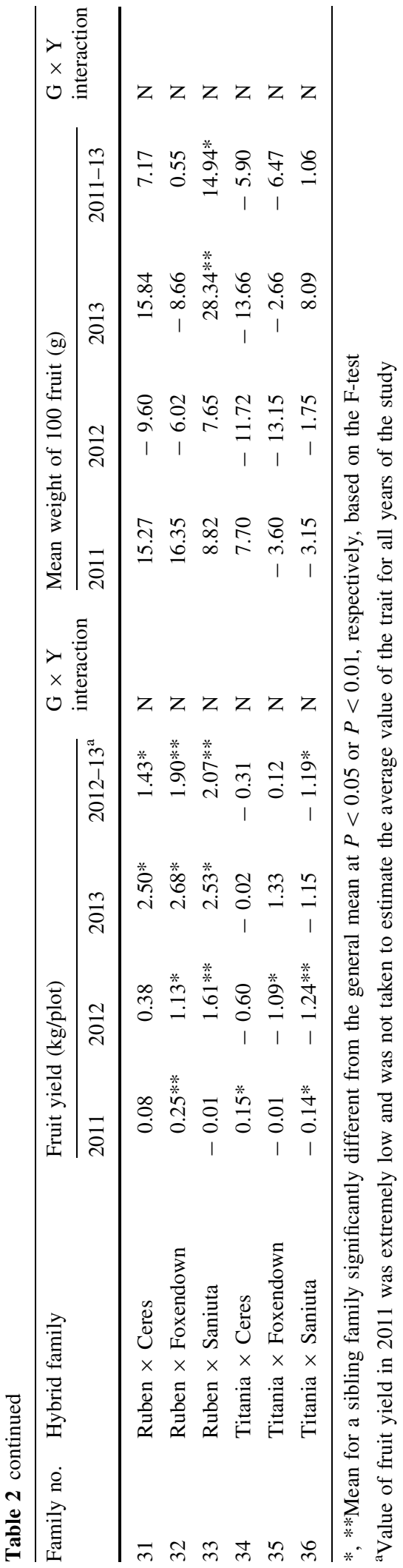

(2007, 2012), had shown that the largest fruit (mean weight of 100 berries ranging from 150 to $218 \mathrm{~g}$ ) was produced by $\mathrm{D} 13 \mathrm{~B} / 11$, and also 'Bona', 'Tihope', 'Saniuta' and 'Sofievskaia'. According to Hummer (2008), the cultivar 'Big Ben' is also included in the group of large-fruited cultivars (mean fruit weight of more than $2 \mathrm{~g}$ ). The smallest fruits in that year were collected from seedlings of the families: 'Kupoliniai' $\times$ 'Foxendown', 'Tihope' $\times$ 'Foxendown' and 'Ores' $\times$ 'Ceres'. Only one hybrid family, 'Sofievskaia' $\times$ 'Saniuta', was shown to have a highly $(P<0.01)$ significant $\mathrm{G} \times \mathrm{Y}$ interaction for fruit weight across the 3 years of evaluation (2011-2013; Table 2), which indicated the high variability of that trait among this family hybrids in different growing seasons.

\section{Soluble solids content}

The content of soluble solids in the fruit of the blackcurrant hybrids was the trait for which there was the highest number of values significantly $(P<0.05)$ different from the general mean (average for all 2160 seedlings; Table 3). The amount of soluble solids content significantly higher than the general mean was found in the fruit of hybrids from 20 families in 2011, 17 families in 2012, and 14 families in 2013. The highest amount of soluble solids content (more than $2.5^{\circ}$ Brix above the general mean) was found in the fruit collected from plants representing the families: 'Tines' $x$ 'Ceres' and 'Tihope' $\times$ 'Saniuta' (2011), 'Gofert' $\times$ 'Foxendown' (2012), 'Gofert' $\times$ 'Saniuta' and 'Kupoliniai' $\times$ 'Ceres' (2013). From previous studies conducted at the Research Institute of Horticulture in Skierniewice (Poland), it followed that the cultivars 'Gofert' and 'Tines' were characterized by a high soluble solids content in the fruit, exceeding $18^{\circ}$ Brix (Pluta et al. 2012; Pluta and Żurawicz 2014), whereas 'Tihope'-by an average level of this component (Pluta and Żurawicz 2015). As it was presented by Pluta et al. (2012) the lowest soluble solids content had the fruits of the cultivars: 'Bona', 'Chereshnieva', 'Saniuta', 'Sofievskaia' and D13B/11. In our studies, for most of the hybrid families, a highly $(P<0.01)$ significant $\mathrm{G} \times \mathrm{Y}$ interaction was estimated for the soluble solids content in the fruit across 2011-2013 (Table 3). It means that the phenotypic value of this trait in the hybrids of these families is not very 


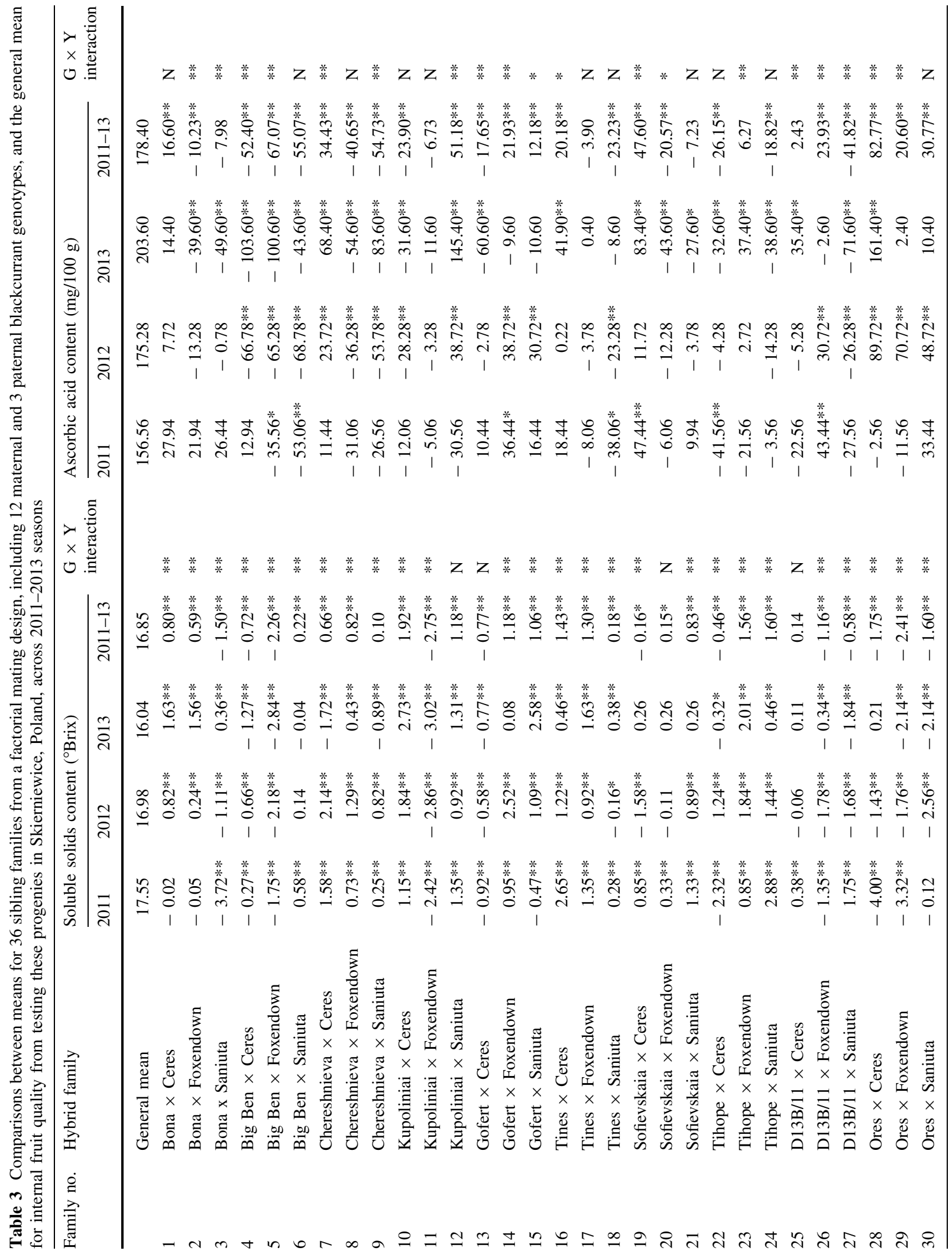




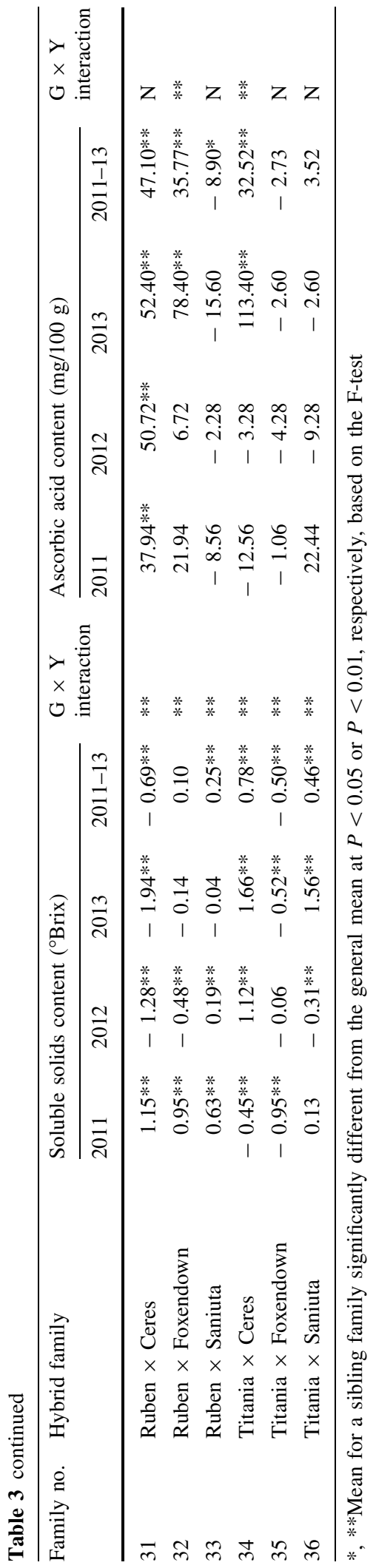

reproducible in different growing seasons. A lack of significant $\mathrm{G} \times \mathrm{Y}$ interaction, indicating high stability of the soluble solids content in the fruit regardless of weather conditions, was found for hybrids of only four families: 'Kupoliniai' $x$ 'Saniuta', 'Gofert' $x$ ' Ceres', 'Sofievskaia' $\times$ 'Foxendown' and D13B/ $11 \times$ 'Ceres'.

\section{Ascorbic acid content}

The ascorbic acid content in the fruit of the evaluated blackcurrant hybrids was quite varied in the years 2011-2013 (Table 3). In 2011, significantly $(P<0.05)$ more ascorbic acid, in comparison with the mean content for the whole population of the evaluated hybrids, was contained in the fruit of the genotypes belonging to four families: 'Gofert' $\times$ 'Foxendown', 'Ruben' $\times$ 'Ceres', D13B/ $11 \times$ 'Foxendown' and 'Sofievskaia' $\times$ 'Ceres'. The lowest ascorbic acid content was in the fruit of the hybrids: 'Big Ben' $\times$ 'Saniuta', 'Tihope' $\times$ 'Ceres', 'Tines' $x$ 'Saniuta' and 'Big Ben' $\times$ 'Foxendown'. In 2012, the richest in ascorbic acid were the berries produced by the seedlings from the families: 'Ruben' $\times$ 'Ceres', 'Ores' $\times$ 'Foxendown' and 'Ores' $\times$ 'Ceres'. For hybrids of eight families, ascorbic acid content in the fruit was found to be significantly lower than the mean value for the entire population; for three families ('Big Ben' $\times$ 'Saniuta', 'Big Ben' $x$ 'Ceres' and 'Big Ben' $\times$ 'Foxendown') the amount of this component was only $106-110 \mathrm{mg} /$ $100 \mathrm{~g}$ fruit $\mathrm{FW}$. The highest mean ascorbic acid content, and also its greatest variation, in the fruit of the hybrids representing the individual families, was found in 2013. Among the hybrids of 10 families with significantly $(P<0.01)$ higher amounts of this component in relation to the mean for all the seedlings, the highest in ascorbic acid were the fruit of hybrids obtained from the crosses of the cultivars 'Ores' $x$ ' Ceres' and 'Kupoliniai' $\times$ 'Saniuta'. As in the 2012 season, the fruits of the hybrids 'Big Ben' $\times$ 'Foxendown' and 'Big Ben' $x$ 'Ceres' were characterized by the lowest levels of this component. Earlier studies by Pluta et al. (2012) had shown that out of 10 blackcurrant cultivars under evaluation the highest ascorbic acid content was in the fruits of 'Gofert', 'Sofievskaia' and 'Tihope', and the lowest in 'Bona', 'Yubyleinaia Kopania' and the clone D13B/11. Among the 36 hybrid families evaluated in our study, a significant 
$\mathrm{G} \times \mathrm{Y}$ interaction for ascorbic acid content in the fruit was estimated for 21 families, and its absence for 15 families (Table 3 ). This means that this trait is not very stable among the hybrids of the majority of the evaluated families in different growing seasons.

\section{Analysis of variance}

The analysis of variance for the hybrid families representing the progeny of 12 maternal and three paternal blackcurrant genotypes crossed in a factorial mating design, conducted on the basis of mean values of the traits evaluated across 2011-2013, showed significant $(P<0.01)$ differences in the effects of the general (GCA) and specific (SCA) combining abilities of the genotypes, as well as their interaction in years of the study $(\mathrm{Y})$ for most of the traits under consideration, with the exception of SCA effects and their interaction with years for the mean fruit weight of 100 berries (Table 4). In order to determine which genetic effects (additive or non-additive) had a predominant share in the determination (inheritance) of a given quantitative trait in the progeny, the general predicted ratio (GPR) was estimated for the GCA and SCA effects of the maternal and paternal cultivars. High GPR values, of both maternal and paternal cultivars, for traits such as fruit yield and mean weight of 100 berries indicate the predominance of additive genetic effects over nonadditive effects in the genetic determination of variability in the above-mentioned quantitative traits in the progeny within the parental gene pool (Baker 1978). Earlier studies by Pluta et al. (2008a, b), based on an evaluation of $F_{1}$ progeny of several dessert blackcurrant cultivars, also showed that the trait of fruit size is mainly determined by additive genetic effects, with very little influence of non-additive effects. This fact indicates that it is relatively easy to breed large-fruited cultivars by using for crosses genotypes with high GCA values for this trait. Indeed, according to biometricians concerned with such analyses, a relatively high GPR value for a given trait indicates high probability of revealing in the progeny a level of that trait which characterizes the average of both parental forms in the progeny (Geleta and

Table 4 Analysis of variance for four traits of 36 sibling families from a factorial mating design, including 12 maternal and 3 paternal blackcurrant genotypes, from testing these progenies in Skierniewice, Poland, across 2011-2013 seasons

\begin{tabular}{|c|c|c|c|c|c|}
\hline \multirow[t]{2}{*}{ Source of variation } & \multirow{2}{*}{$\begin{array}{l}\text { Degrees of } \\
\text { freedom }\end{array}$} & \multicolumn{4}{|c|}{ Mean of squares } \\
\hline & & $\begin{array}{l}\text { Fruit yield } \\
\text { (kg/plot) }\end{array}$ & $\begin{array}{l}\text { Mean weight of } 100 \\
\text { fruit }(\mathrm{g})\end{array}$ & $\begin{array}{l}\text { Soluble solids } \\
\text { content }\left({ }^{\circ} \text { Brix }\right)\end{array}$ & $\begin{array}{l}\text { Ascorbic acid content } \\
(\mathrm{mg} / 100 \mathrm{~g})\end{array}$ \\
\hline Years & 2 & $271.19 * *$ & $498.78 * *$ & $20.84 * *$ & $201.93 * *$ \\
\hline Genotypes & 35 & $2.51 * *$ & $368.19 * *$ & $4.30 * *$ & $34.92 * *$ \\
\hline $\begin{array}{l}\text { Genotype } \times \text { year } \\
\text { interaction }(\mathrm{G} \times \mathrm{Y})\end{array}$ & $70\left(35^{\mathrm{b}}\right)$ & $1.18^{\mathrm{b} * *}$ & $96.47 * *$ & $1.20 * *$ & $12.00 * *$ \\
\hline $\begin{array}{l}\text { GCA of maternal } \\
\text { genotypes }\end{array}$ & 11 & $1.71 * *$ & $191.20 * *$ & $1.97 * *$ & $18.70 * *$ \\
\hline GCA of paternal genotypes & 2 & $0.44^{\mathrm{n}}$ & $203.72 * *$ & $0.18 * *$ & $4.48 * *$ \\
\hline $\begin{array}{l}\text { GCA of mothers } \times \text { years } \\
\left(\mathrm{GCA}^{+} \times \mathrm{Y}\right)\end{array}$ & $22\left(11^{b}\right)$ & $0.76^{\mathrm{b} * *}$ & $41.42 * *$ & $0.56 * *$ & $4.61 * *$ \\
\hline $\begin{array}{l}\text { GCA of fathers } \times \text { years } \\
\left(\text { GCA }^{\hat{\delta}} \times Y\right)\end{array}$ & $4\left(2^{b}\right)$ & $0.21^{\mathrm{b}}$ & $24.72 * *$ & $0.04 * *$ & $1.26^{* *}$ \\
\hline SCA & 22 & $0.94 * *$ & $76.72^{\mathrm{n}}$ & $3.69 * *$ & $22.61 * *$ \\
\hline SCA $\times$ years $(\mathrm{SCA} \times \mathrm{Y})$ & $44\left(22^{\mathrm{b}}\right)$ & $0.51^{\mathrm{b} * *}$ & $64.37^{\mathrm{n}}$ & $1.03 * *$ & $10.81 * *$ \\
\hline $\mathrm{GPR}^{\text {+a }}$ & & 0.78 & 0.83 & 0.52 & 0.62 \\
\hline $\mathrm{GPR}^{\widehat{\gamma} \mathrm{a}}$ & & 0.48 & 0.84 & 0.09 & 0.28 \\
\hline
\end{tabular}

*, **Significant differences of GCA or SCA effects at $P<0.05$ or $P<0.01$, respectively, based on the $\mathrm{F}$ test ${ }^{\mathrm{a}} \mathrm{GPR}$ - the general predicted ratio for the traits calculated as follows: GCA/SCA $=\left(2 \mathrm{MS}_{\mathrm{GCA}}\right) /\left(2 \mathrm{MS}_{\mathrm{GCA}}+\mathrm{MS}_{\mathrm{SCA}}\right)$

${ }^{b}$ Genotype $\times$ year interaction was estimated only for 2012 and 2013, because of extremely low value of fruit yield in the first year of evaluation (2011) 
Labuschagne 2006). Pluta et al. (2008a, b) also found a large discrepancy in the GPR values estimated for blackcurrant yields in the individual years of research (from 0.24 to 0.70 ), which they justified by stronger influence of non-additive effects on the manifestation of this trait, as well as by the occurrence of a strong genetic-environmental correlation. Similar studies, conducted for several gooseberry (Ribes grossularia) cultivars, showed that fruit size was mainly determined by additive genetic effects, whereas productivity-only by non-additive effects (Pluta et al. 2014). The GPR values for the soluble solids and ascorbic acid contents in the fruit indicate that these traits are determined by both additive and non-additive genetic effects originating from the maternal and paternal cultivars, with the contribution of the additive effects of maternal forms to the emergence of these traits in the progeny being higher than that of paternal forms. The available literature information on the genetic determination of fruit quality traits of species and varieties of the genus Ribes is generally related to fruit size and colour (Pluta et al. 2008a, b, 2014; Pluta and Żurawicz 2009), and there is no data on how internal quality traits are inherited, most likely due to the labour-intensive and costly nature of chemical analyses of the fruit of numerous genotypes representing the gene pool of interest.

\section{Analysis of GCA effects of parental genotypes}

The estimates of the GCA effects of blackcurrant parental forms in terms of fruit yield and weight of 100 berries, as well as the content of soluble solids and ascorbic acid in the individual years of the study are presented in Tables 5 and 6. For each of these traits and each year of the evaluation, GCA effects with statistically $(P<0.05)$ proven values were found.

\section{Fruit yield}

Significant $(P<0.05)$ GCA effects for the parental genotypes evaluated in terms of fruit yield were generally obtained only in one or two, less frequently in all 3 years of the study, and also for the mean value of the 3 years (Table 5). However, fruit yield in the first year of evaluation was very low and was not considered for estimation of the average GCA effect for the trait. The highest values of GCA effects for this trait across 2012-2013 were estimated for the cultivars 'Big Ben' and 'Ruben'. The first of these cultivars, 'Big Ben', was described in the literature as highly productive (Hummer 2008). The cultivar 'Ruben' bred and evaluated at the Research Institute of Horticulture in Skierniewice, Poland, produced fruit yields by 40-45\% higher than the Swedish cultivar 'Titania' (Pluta et al. 2008a, b). At the same time, a significant $(P<0.05)$ GCA $\times \mathrm{Y}$ interaction was estimated for 'Ruben', which might cause difficulties in unambiguously evaluating its general combining ability. Significantly $(P<0.05)$ positive average GCA effect across 2012-2013 was also found for the clone D13B/ 11. Except this genotype, also 'Gofert' 'Saniuta' and 'Foxendown' had the significant and positive GCA effects in one of the tested years. Thus, it could be expected that the progeny of these genotypes would be characterized by high fruit productivity. However, in the case of the cultivar 'Foxendown', the assessment appeared to be much less reliable than for the cultivar 'Saniuta', because the high GCA $\times$ Y interaction estimated for 'Foxendown' indicated unstable yielding in varying weather conditions. In addition, in previous studies at the Research Institute of Horticulture (Pluta et al. 2007), the cultivar 'Foxendown' was significantly less productive than 'Titania'. Significantly $(P<0.05)$ negative GCA effects for fruit yield were shown by the cultivar 'Bona' in all years of the study, and also by the cultivars 'Tines', 'Sofievskaia', 'Tihope' and 'Ceres' in two consecutive growing seasons. It could be concluded that these cultivars were of little use for the applied blackcurrant breeding because they passed on a low productivity to their progenies. The low breeding value of the cultivar 'Bona' (significantly negative GCA effects) for plant productivity was earlier proven by evaluating the diallel progeny of six dessert cultivars of blackcurrant (Pluta et al. 2008a, b). Single, statistically proven $(P<0.01)$ GCA effects with negative values for fruit yield were also found for the cultivars 'Kupoliniai' and 'Titania'. Earlier investigations of the combining ability of the cultivar 'Titania', conducted by Pluta et al. (1993) on the basis of an evaluation of $F_{1}$ progeny obtained by crossing this cultivar in a diallel mating design with the cultivars 'Ben Nevis', 'Bieloruskaia Slodkaia', 'Consort' and 'Ojebyn', had shown that 'Titania' was recognized as a donor of high fruit yield. However, the same cultivar, tested 20 years later in crosses with newer dessert cultivars of 


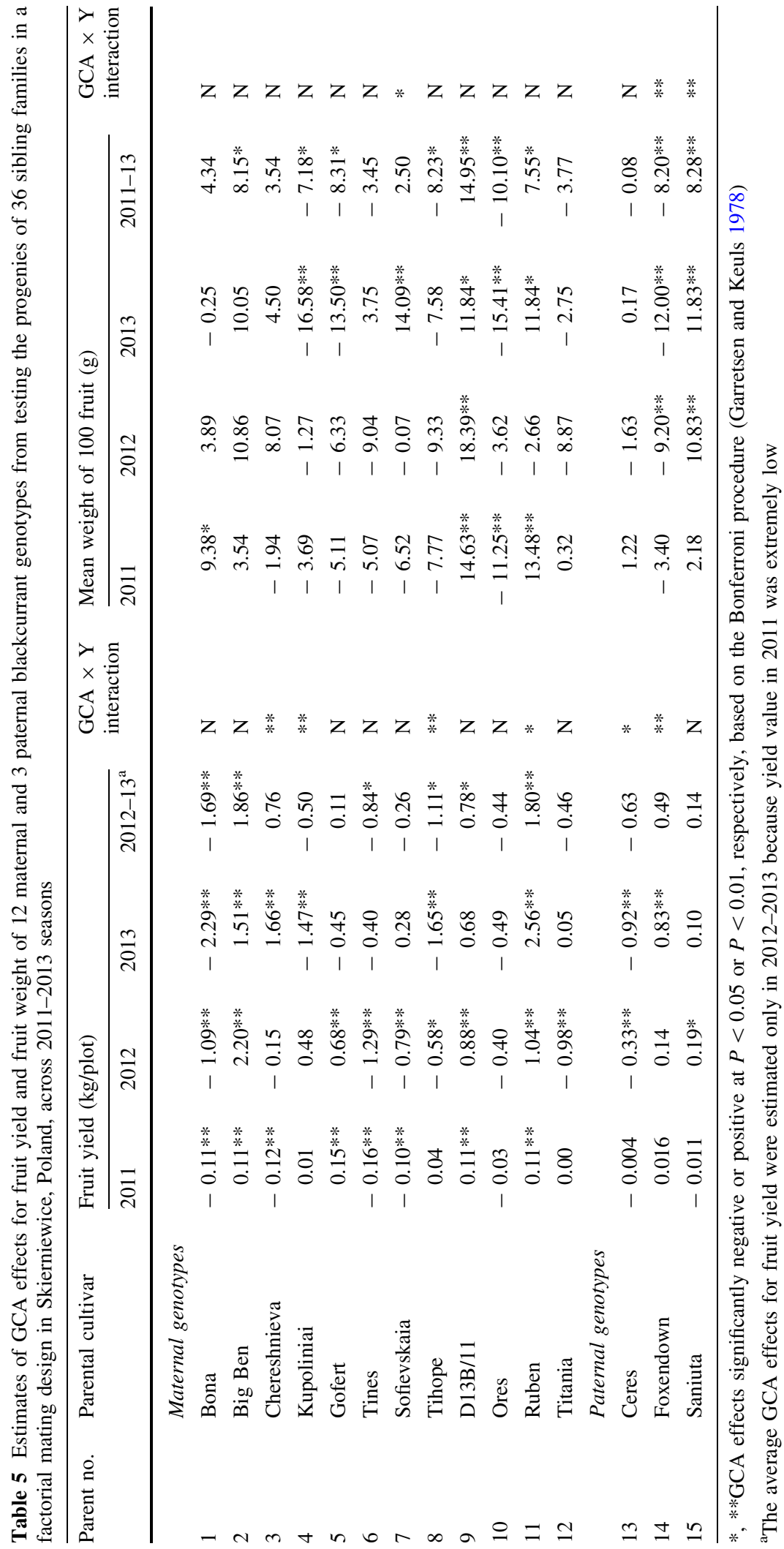




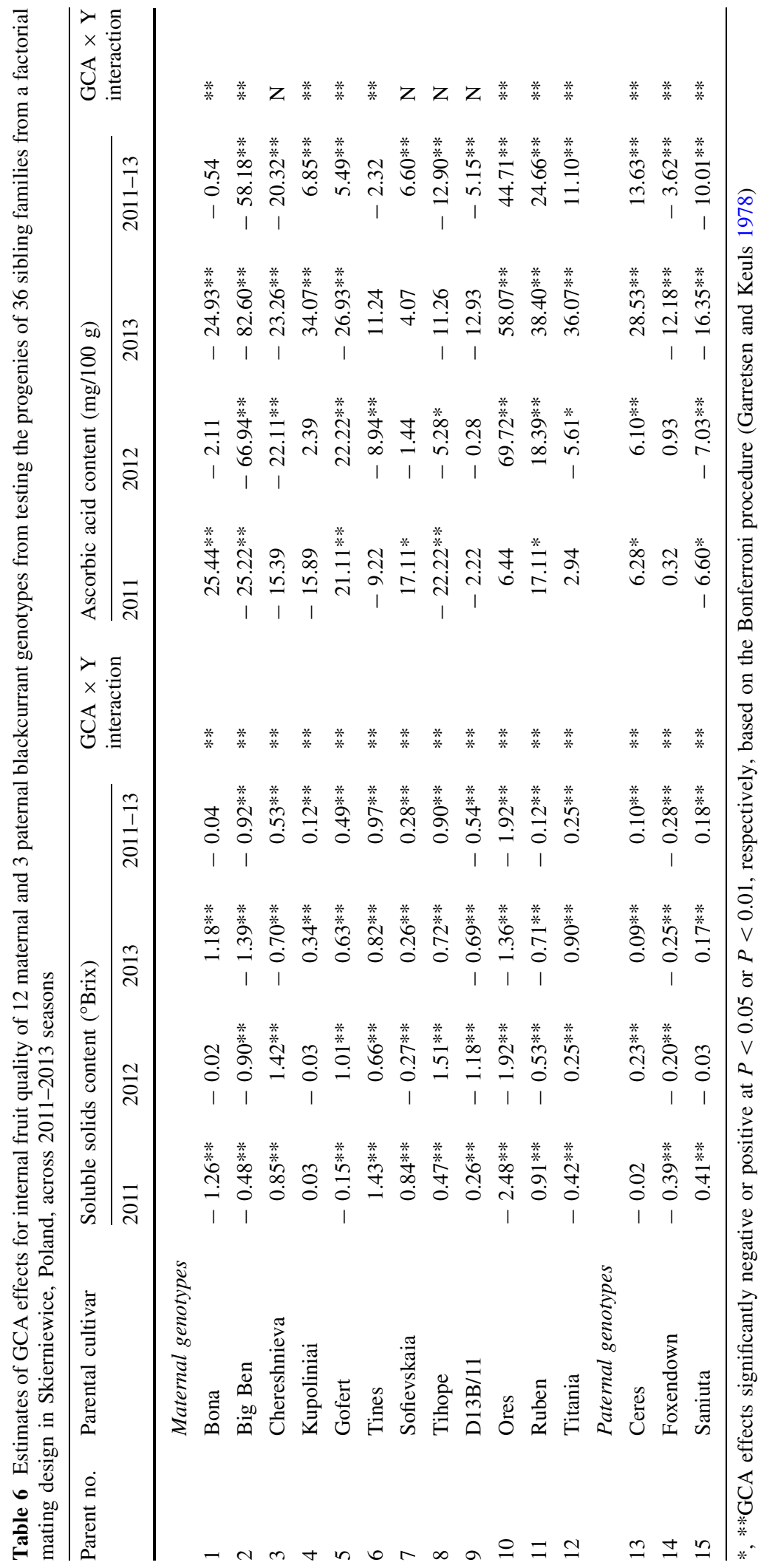


blackcurrant, proved to be of little use as a parent in breeding of new high-yielding cultivars. For the cultivar 'Chereshnieva', a total of two significant GCA effects for fruit yield were estimated - one with a positive value (2013), and the other one with a negative value (2011). The low stability of this cultivar in terms of the fruit productivity trait was also confirmed by the highly significant $(P<0.01)$ GCA $\times$ Y interaction. Similar results related to the cultivar 'Chereshnieva' was also obtained in earlier studies conducted at the Research Institute of Horticulture in Skierniewice, Poland (Pluta et al. 2008a, b). In those studies, during 4 years of fruiting, this cultivar had GCA effects close to zero, with negative values in the first two seasons and positive ones in the subsequent two seasons. A significant $(P<0.01)$ GCA $\times$ Y interaction was also proven for cultivar 'Kupoliniai'. Unfortunately, the occurrence of a strong GCA $\times$ Y interaction might create great difficulty in unambiguously evaluating the breeding value of parental forms based on their GCA effects (Shaw et al. 2005).

\section{Fruit weight}

Statistically proven $(P<0.05)$ GCA effects for the mean weight of 100 berries were observed, for most of the genotypes under evaluation, generally only in 1 or 2 years of the study (Table 5). The only genotype for which the significant GCA effects for this trait were positive across all the years of the study was D13B/11. This genotype, bred at the Research Institute of Horticulture in Skierniewice, was characterized by very large berries, with an average weight of more than $2.2 \mathrm{~g}$ (Pluta et al. 2012). Significant GCA effects for fruit weight in two out of the 3 years of the study were estimated for four parental genotypes; for the cultivars 'Ruben' and 'Saniuta' they were positive, while for the cultivars 'Ores' and 'Foxendown' they were negative. One significant $(P<0.05)$ GCA effect for fruit weight in the three-year period of the study was demonstrated for each of four genotypes. In the case of the cultivars 'Kupoliniai' and 'Gofert', these effects were negative, while for 'Sofievskaia' and 'Bona'-positive. The results obtained for the latter cultivar differ from previous studies in which significantly negative GCA effects were estimated for this trait (Pluta et al. 2008a, b). It was shown that the cultivar 'Bona' passed on to its progeny the ability to bear small berries, despite of producing large berries itself (Pluta et al. 2012). For the cultivar 'Big Ben', all the estimated GCA effects for fruit size were positive, but their significance $(P<0.05)$ was confirmed only for the mean fruit weight obtained across the three growing seasons. However, earlier studies by Pluta and Żurawicz (2009) were shown that this cultivar was a donor of high fruit weight. The cultivars 'Ores', 'Foxendown', 'Kupoliniai' and 'Gofert', for which the statistically proven GCA effects were negative, were not very useful for cross-breeding programmes aimed at producing large-fruited cultivars, because their progeny would bear small berries. A significant $(P<0.05)$ GCA $\times$ Y interaction was found only for three genotypes: 'Sofievskaia', 'Foxendown' and 'Saniuta'.

\section{Soluble solids content}

The largest number of statistically proven $(P<0.01)$ GCA effects was estimated for the soluble solids content in the blackcurrant fruit (Table 6). Most genotypes showed significant GCA effects in all the years of the evaluation; for the remaining four cultivars, one or two significant GCA effects were demonstrated. However, for this trait, a high $(P<0.01)$ GCA $\times$ Y interaction was also found for all the evaluated genotypes, indicating their high genetic instability. For seven genotypes ('Bona', 'Chereshnieva', 'Gofert', 'Sofievskaia', 'Ruben', 'Titania' and D13B/11), the GCA effects obtained for the soluble solids content in the fruit in the individual years took on both positive and negative values, which confirms the low reproducibility of this trait across the years. For the genotypes 'Tines' and 'Tihope', the GCA effects had positive values in all the years of the study, meaning that these cultivars are highly useful for breeding of new blackcurrant varieties with increased extract content in the fruit. The GCA effects estimated for the cultivars 'Big Ben', 'Ores' and 'Foxendown' were negative, so these cultivars are donors of low soluble solids content in the fruit of their offspring.

\section{Ascorbic acid content}

Statistically proven $(P<0.05)$ GCA effects for the ascorbic acid content in the fruit were estimated for 
most of the evaluated blackcurrant genotypes, generally only in 1 or 2 years of the study (Table 6). GCA effects with positive values for this trait were found for the cultivars 'Ruben' and 'Ceres' in all the years of evaluation, and also for 'Ores' in 2012-2013 and 'Kupoliniai' and 'Sofievskaia' in 1 year of the study. The results showed that these cultivars are donors of high ascorbic acid content in the fruit and could be very suitable for breeding of innovative dessert type cultivars reach in that beneficial component for human health. The cultivars 'Big Ben' and 'Saniuta' had significantly $(P<0.05)$ negative GCA effects in all the years of the evaluation, 'Chereshnieva' and 'Tihope' in two seasons, while 'Tines' and 'Foxendown' only in 1 year of the evaluation. That indicates their limited usefulness for the applied blackcurrant breeding aimed at obtaining dessert cultivars with high ascorbic acid content in fruits. For cultivars 'Bona', 'Gofert' and 'Titania', the GCA effects for the ascorbic acid content in the fruit took on both positive and negative values in the individual years, which indicates low reproducibility of this trait across the years and it is confirmed by the highly significant $(P<0.01)$ GCA $\times$ Y interaction. Only for four parental genotypes ('Chereshnieva', 'Sofievskaia', 'Tihope' and D13B/11) the estimated GCA $\times$ Y interaction was not significant. It indicates high stability of the trait in the tested hybrids despite of the distinctly different weather conditions in the individual years of studies.

\section{Analysis of SCA effects for hybrid families}

The estimates of the SCA effects of the blackcurrant hybrid families evaluated in terms of fruit yield and weight of 100 berries, as well as soluble solids and ascorbic acid contents in the individual years of the study are presented in Tables 7 and 8 . For each of these traits, SCA effects with statistically proven $(P<0.05)$ values were found in at least 1 year of the evaluation.

\section{Fruit yield}

With regard to the average fruit yield (2012-2013), significant $(P<0.05)$ SCA effects, indicating genetic interaction of both parental genotypes in the manifestation of this trait in the progeny, were shown by four hybrid families (Table 7). Two of the families: 'Big
Ben' $\times$ 'Saniuta' and D13B/11 $\times$ 'Ceres' had the positive SCA effects in 2012 and for the average in 2012-2013. Considering that only one parental form in both the cross combinations had statistically significant values of GCA effects, the great importance of interaction in the inheritance of this trait should be emphasized, because these hybrids were expected to have much higher fruit yield than that resulting from the sum of the GCA effects for their parental forms. In 2011 the significantly positive SCA effects were estimated for two other families: 'Ruben' $\times$ 'Foxendown' and 'Titania' $\times$ 'Ceres'. However, fruit yield of such very young hybrids was very low in 2011 and should not be taken into consideration for determination of the SCA effects for the trait. The statistically proven $(P<0.05)$ SCA effects with negative values for this trait were demonstrated for the following families: 'Ores' $x$ ' Ceres' (2011 and 2013 seasons, and the average for 2012-2013), D13B/11 × 'Saniuta' (2012 and the average for 2012-2013), 'Big Ben' $\times$ 'Foxendown' (2012), 'Gofert' $\times$ 'Foxendown' (2011) and 'Titania' $\times$ 'Saniuta' (2011). No significant SCA $\times$ Y interaction was found for any of the tested hybrid families. This means that under varied weather conditions in consecutive growing seasons the interaction of both parental forms of these hybrids in the formation of fruit crop in their progeny is stable.

\section{Fruit weight}

For the trait-mean weight of 100 berries, only one statistically proven $(P<0.05)$ SCA effect was found in the 3 years of the study (Table 7). That effect had a positive value and was found in 2011, only for the family 'Chereshnieva' $x$ 'Saniuta'. This family is thus expected to have numerous progeny with large fruit. However, the high value of the quotient of the mean square deviations of GCA and SCA effects for this trait indicates that the trait of bearing large berries is not determined solely by the interaction effects of both parental genotypes, but is also the result of the high general combining ability of the cultivar 'Saniuta'. No SCA $\times$ Y interactions were found for any of the 36 hybrid families under evaluation. 


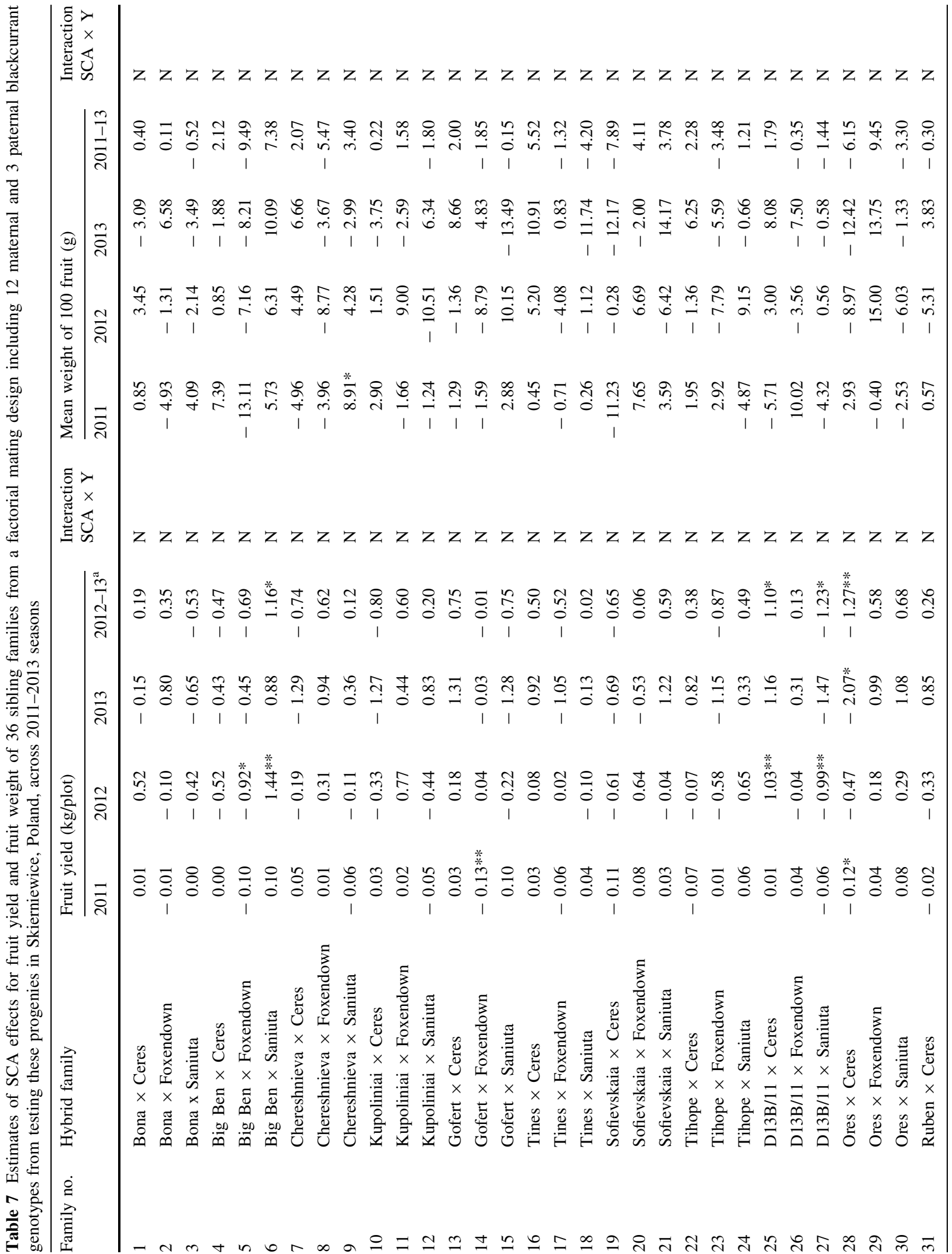




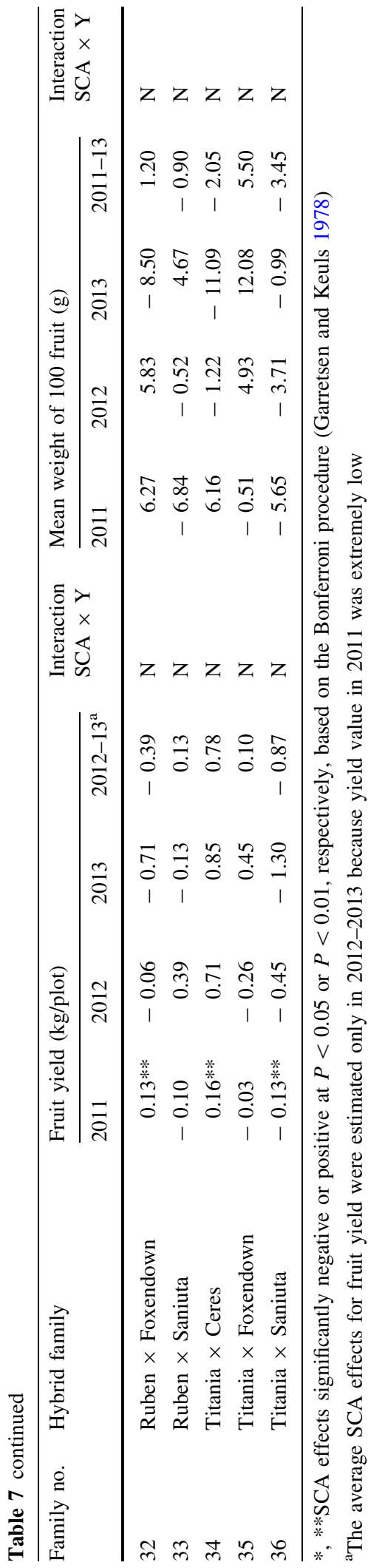

\section{Soluble solids content}

The highest number of statistically proven $(P<0.05)$ SCA effects was found in relation to the soluble solids content in blackcurrant fruit (Table 8). Most of the hybrid families had significant SCA effects in all the years of the evaluation; only in the case of three families did the estimated SCA effects apply to only 1 year, and for 5 families -2 years of the study. For 13 hybrid families, the obtained SCA effects for the soluble solids content in the fruit in the individual years took on both positive and negative values, which indicate their low genetic stability. That was also confirmed by the highly significant $(P<0.01)$ SCA $\times$ $\mathrm{Y}$ interaction estimated for these families. Significant $(P<0.01)$ SCA effects with positive values in all the years of the evaluation were estimated for the following hybrid families: 'Bona' $\times$ 'Ceres', 'Bona' $\times$ 'Foxendown', 'Big Ben' $\times$ 'Saniuta', 'Kupoliniai' $\times$ 'Ceres', 'Kupoliniai' $\times$ 'Saniuta', 'Tines' $\times$ 'Foxendown', 'Tihope' $\times$ 'Foxendown', $\mathrm{D} 13 \mathrm{~B} / 11 \times$ 'Ceres' and 'Ruben' $\times$ 'Foxendown'. Therefore, it should be expected that the fruit of the hybrids of these families will be rich in soluble solids despite of the fact that some of these parental forms are characterized by a low GCA for this trait. Significantly $(P<0.01)$ negative SCA effects in all the years of the study were found for seven families: 'Bona' $\times$ 'Saniuta', 'Big Ben' $\times$ 'Foxendown', 'Chereshnieva' $\times$ 'Saniuta', 'Kupoliniai' $\times$ 'Foxendown', 'Gofert' $\times$ 'Ceres', 'Tines' $\times$ 'Saniuta' and 'Tihope' $\times$ 'Ceres'. This means that the progeny of these families will produce berries with low soluble solids content. Considering that the pedigrees of the hybrids of most of these families include cultivars with a high general combining ability for this trait ('Saniuta', 'Ceres', 'Kupoliniai', 'Gofert', 'Tines', 'Tihope' and 'Chereshnieva'), the occurrence of interaction effects of both parents is in this case undesirable because it causes a deterioration in the value of their progeny.

\section{Ascorbic acid content}

Statistically proven $(P<0.05)$ SCA effects for the ascorbic acid content in the fruit were found, for most of the hybrid families under evaluation, generally only in 1 or 2 years of the study (Table 8). Significant SCA effects in all the years of the study were found only for 


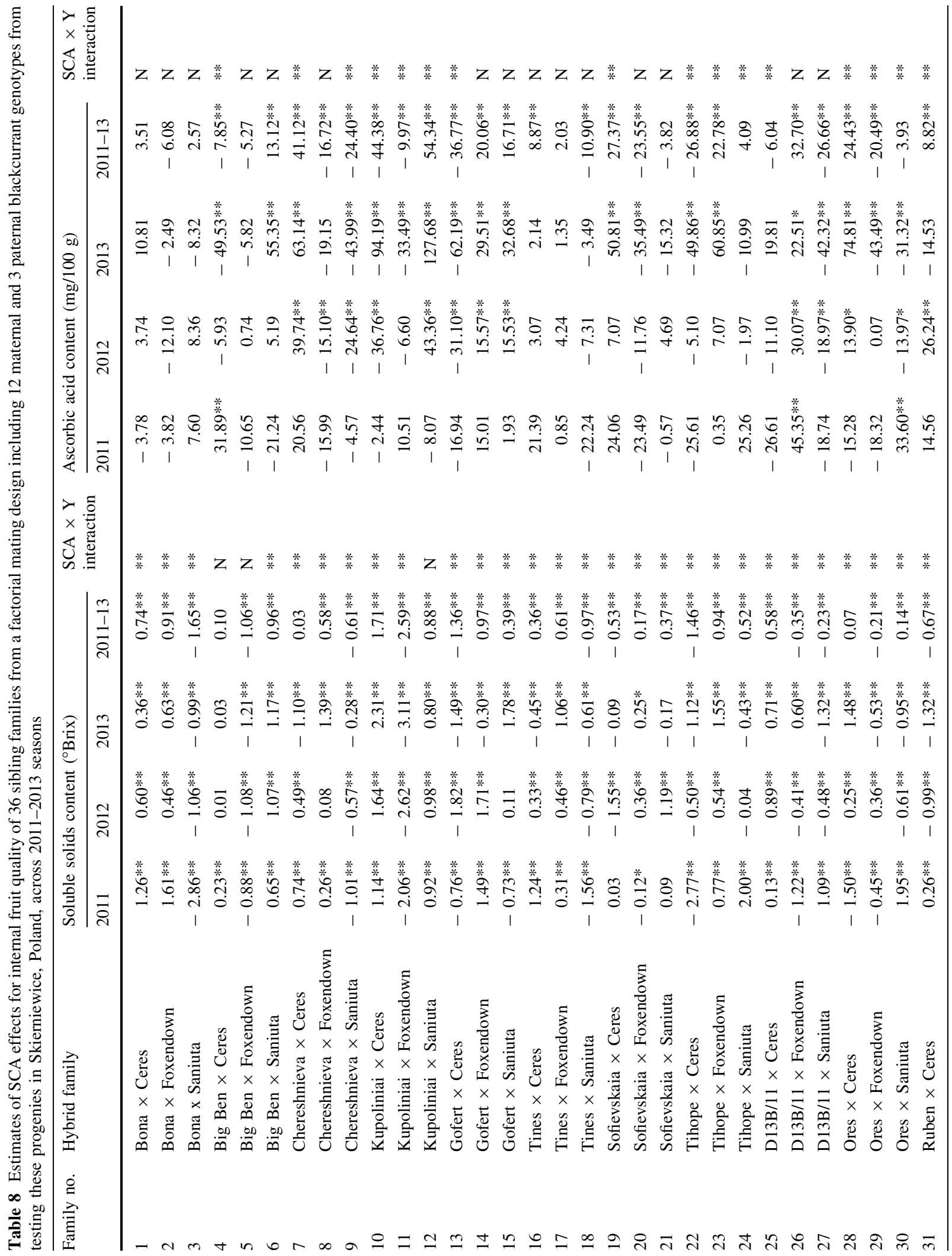




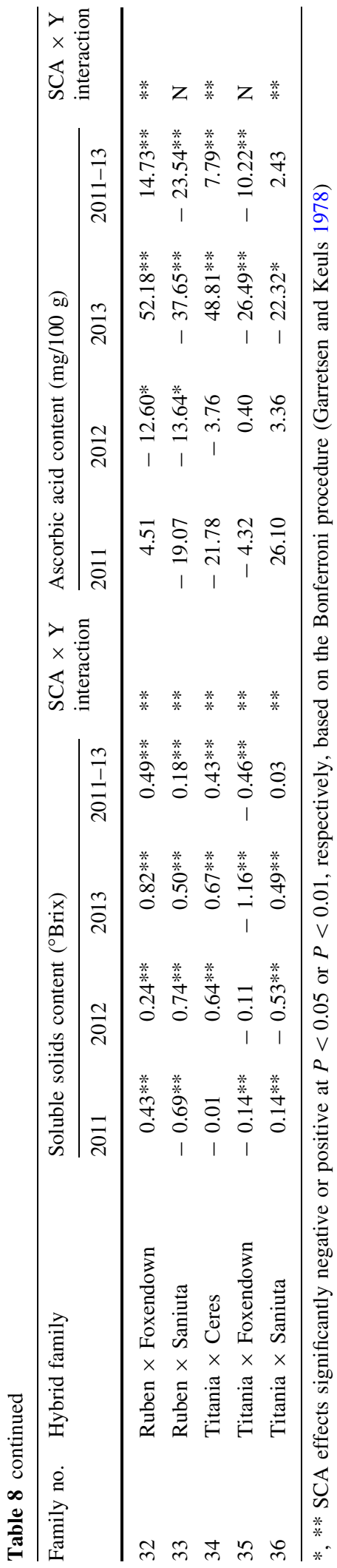

two hybrid families. For the family D13B/11 × 'Foxendown', these effects always had positive values, but for the family 'Ores' $\times$ 'Saniuta' they varied-in the 2011 season they were positive, while in 2012 and 2013 - negative. Significantly $(P<0.05)$ positive SCA effects for ascorbic acid content in the fruit in two consecutive growing seasons (and also in the case of the mean value for all the years of the study) were shown by the families: 'Chereshnieva' $\times$ 'Ceres', 'Kupoliniai' $\times$ 'Saniuta', 'Gofert' $\times$ 'Foxendown', 'Gofert' $\times$ 'Saniuta' and 'Ores' $\times$ 'Ceres'. This means that for these families, as well as for the previously mentioned family D13B/11 × 'Foxendown', the genetic interaction of both parental genotypes determines high ascorbic acid content in their progeny. The statistically proven $(P<0.05)$ SCA effects with negative values for this trait in two successive years of the evaluation were shown for the families: 'Chereshnieva' $\times$ 'Saniuta', 'Kupoliniai' $\times$ 'Ceres', 'Gofert' $\times$ 'Ceres', D13B/11 × 'Saniuta', 'Ores' $\times$ 'Saniuta' and 'Ruben' $\times$ 'Saniuta'. For 19 of the 36 hybrid families, a highly significant $(P<0.01)$ SCA $\times$ Y interaction was also estimated. For the following families: 'Bona' $\times$ 'Ceres', 'Bona' $\times$ 'Foxendown', 'Bona' $\times$ 'Saniuta', 'Big Ben' $\times$ 'Foxendown', 'Big Ben' $\times$ 'Saniuta', 'Chereshnieva' $\times$ 'Foxendown', 'Gofert' $\times$ 'Foxendown', 'Gofert' $\times$ 'Saniuta', 'Tines' $\times$ 'Ceres', 'Tines' $\times$ 'Foxendown', 'Tines' $\times$ 'Saniuta', 'Sofievskaia' $\times$ 'Foxendown', 'Sofievskaia' $\times$ 'Saniuta', D13B/11 × 'Foxendown', D13B/11 × 'Saniuta', 'Ruben' $\times$ 'Saniuta' and 'Titania' $\times$ 'Foxendown' the SCA $\times$ Y interaction was insignificant, as it was proved in our studies.

\section{Conclusions}

The analysis of general and specific combining abilities of the 15 blackcurrant genotypes evaluated for the traits of interest indicates that they have different usefulness as potential parental forms for the applied breeding of new blackcurrant cultivars with high productivity and fruit quality. The most useful genotypes for this breeding direction are: 'Ruben' (significantly positive GCA effects for fruit yield, mean fruit weight and ascorbic acid content), 'Big Ben' and D13B/11 (significantly positive GCA effects for fruit yield and mean fruit weight), 'Saniuta' 
(significantly positive GCA effects for mean fruit weight and soluble solids content), and also 'Kupoliniai', 'Gofert', 'Sofievskaia', 'Titania' and 'Ceres' (significantly positive GCA effects for extract and ascorbic acid contents in the fruit). The least useful for breeding of prolific varieties with high fruit quality are 'Bona' and 'Foxendown'. In view of the highly significant positive SCA effects for two or three traits and the simultaneous lack of significant negative effects (for data averaged over the 3 years of the study) were estimated for the hybrid families: 'Big Ben' $\times$ 'Saniuta', 'Ruben' $\times$ 'Foxendown', 'Titania' $\times$ 'Ceres', 'Kupoliniai' $\times$ 'Saniuta', 'Gofert' $\times$ 'Foxendown', 'Gofert' $\times$ 'Saniuta', 'Tines' $\times$ 'Ceres' and 'Tihope' $\times$ 'Foxendown', these combinations should be included in cross-breeding programmes aimed at developing of new dessert type blackcurrant cultivars.

The analysed functional traits of blackcurrant genotypes (fruit yield, fruit weight and the soluble solids and ascorbic acid contents) are determined by both additive and non-additive genetic effects. However, in the inheritance of traits such as fruit yield and fruit weight, the additive effects play a dominant role.

Acknowledgements We thank Dr. Dorota Jarret, James Hutton Limited, Errol Road, Invergowrie, Dundee DD2 5DA, Scotland, UK, for English language revisions of the manuscript. This study was funded by the Polish Ministry of Agriculture and Rural Development ("Basic research for the biological progress"-grant 107 "Studies on the possibility of obtaining the dessert-type blackcurrant cultivars by intra- and interspecific hybridization within the genus Ribes").

Open Access This article is distributed under the terms of the Creative Commons Attribution 4.0 International License (http:// creativecommons.org/licenses/by/4.0/), which permits unrestricted use, distribution, and reproduction in any medium, provided you give appropriate credit to the original author(s) and the source, provide a link to the Creative Commons license, and indicate if changes were made.

\section{References}

Baker RJ (1978) Issues in diallel analysis. Crop Sci 18:533-536 Bestfleisch M, Möhring J, Hanke MV, Peil A, Flachowsky H (2014) A diallel crossing approach aimed on selection for ripening time and yield in breeding of new strawberry (Fragaria $\times$ ananassa Duch.) cultivars. Plant Breed 133:115-120
Blackcurrant Foundation (2017) Blackcurrant fruit composition. www.blackcurrantfoundation.co.uk/blackcurrantshealth/scientific-research/blackcurrant-fruit-composition. Accessed 18 Apr 2017

Bordonaba GJ, Terry LA (2008) Biochemical profiling and chemometric analysis of seventeen UK-grown blackcurrant cultivars. J Agric Food Chem 56:7422-7430. https:// doi.org/10.1021/jf8009377

Brennan RM (2008) Currants and gooseberries. In: Hancock JF (ed) Temperate fruit crop breeding: germplasm to genomics, 1st edn. Springer, Amsterdam, pp 177-196

Brennan R, Graham J (2009) Improving fruit quality in Rubus and Ribes through breeding. Funct Plant Sci Biotechnol 3:22-29

Fort SB, Shaw DV (2000) Genetic analysis of strawberry root system traits in fumigated and nonfumigated soils. I. Inheritance patterns of strawberry root system characteristics. J Am Soc Hortic Sci 125:318-323

Garretsen F, Keuls M (1978) A general method for the analysis of genetic variation in complete and incomplete diallels and North Carolina II (NC II) designs. Part II. Procedures and general formulas for the fixed model. Euphytica 27:49-68

Geleta LF, Labuschagne MT (2006) Combining ability and heritability for vitamin $\mathrm{C}$ and total soluble solids in pepper (Capsicum annuum L.). J Sci Food Agric 86:1317-1320

Griffing B (1956a) A generalised treatments of diallel crosses in quantitative inheritance. Heredity 10:31-50

Griffing B (1956b) Concept of general and specific combining ability in relation to diallel crossing systems. Aust J Biol Sci 9:463-493

Hancock RD, Walker PG, Pont SDA, Marquis N, Vivera S, Gordon SL, Brennan RM, Viola R (2007) L-ascorbic acid accumulation in fruit of Ribes nigrum occurs by in situ biosynthesis via the L-galactose pathway. Funct Plant Biol 34:1080-1091. https://doi.org/10.1071/FP07221

Hummer KE (2008) Currant. In: Finn CE, Clark JR (eds) Register of new fruit and nut varieties-List 44, vol 43. HortScience, pp 1321-1343

Hummer KE, Barney D (2002) Crop reports. Currants. Hortic Technol 12:377-387

Kaldmäe H, Kikas A, Arus L, Libek AV (2013) Genotype and microclimate conditions influence ripening pattern and quality of blackcurrant (Ribes nigrum L.) fruit. Zemdirb Agric 100:167-174. https://doi.org/10.13080/z-a.2013. 100.021

Masny A, Pruski K, Żurawicz E, Mądry W (2016a) Breeding value of selected dessert strawberry (Fragaria $x$ ananassa Duch.) cultivars for ripening time, fruit yield and quality. Euphytica 207:225-243. https://doi.org/10.1007/s10681015-1480-6

Masny A, Masny S, Żurawicz E, Pruski K, Mądry W (2016b) Suitability of certain strawberry genotypes for breeding of new cultivars tolerant to leaf diseases based on their combining ability. Euphytica 210:341-366. https://doi.org/ 10.1007/s10681-016-1690-6

Möhring J, Piepho HP (2009) Comparison of weighting in twostage analyses of series of experiments. Crop Sci 49:1977-1988. https://doi.org/10.2135/cropsci2009.02. 0083 
Muszyński S (2000) Genetyka dla rolników. Fundacja "Rozwój SGGW", Warszawa

Nduwumuremyi A, Tongoona P, Hapimana S (2013) Mating design: helpful tool for quantitative plant breeding analysis. J Plant Breed Genet 01:117-129

Pluta S, Żurawicz E (2009) Dessert-type cultivars of blackcurrant (Ribes nigrum L.) - new breeding aiming at the RIPF, Skierniewice, Poland. J Jilin Agric Univ 31:481-485

Pluta S, Żurawicz E (2014) 'Gofert' blackcurrant. HortScience 49:513-515

Pluta S, Żurawicz E (2015) 'Tihope' blackcurrant. HortScience 50:1096-1098

Pluta S, Żurawicz E, Mądry W (1993) Phenotypic and breeding values of few blackcurrant cultivars in Central Poland. Acta Hortic 352:455-462

Pluta S, Żurawicz E, Broniarek-Niemiec A (2007) Wartość produkcyjna nowych odmian i klonów hodowlanych porzeczki czarnej oceniana w latach 2000-2006. Roczniki Akademii Rolniczej w Poznaniu CCCLXXXIII, Ogrodnictwo 41:371-376

Pluta S, Mądry W, Żurawicz E (2008a) General combining ability of selected blackcurrant (Ribes nigrum L.) genotypes in breeding for dessert quality fruit. Acta Hortic 777:57-60

Pluta S, Żurawicz E, Krawiec A, Salamon Z (2008b) Evaluation of the suitability of Polish blackcurrant cultivars for commercial cultivation. J Fruit Ornam Plant Res 16:153-166

Pluta S, Żurawicz E, Pruski K (2012) Suitability of fruits of selected blackcurrant (Ribes nigrum L.) cultivars for fresh market. J Berry Res 2:23-31
Pluta S, Żurawicz E, Studnicki M, Mądry W (2014) Combining ability analysis for selected plant traits in gooseberry. J Am Soc Hortic Sci 139:1-11

Ravkin AS (1981) Analysis of field resistance of blackcurrant to the American gooseberry mildew by estimation the combining ability of the varieties. Genetika, Tom XVII 11:1998-2003

Shaw DV, Gordon TR, Larson KD, Kirkpatrick SC (2005) The effect of Verticillium infection in runner plant propagation nurseries on resistant and susceptible strawberry genotypes. J Am Soc Hortic 130:707-710

Vagiri M (2012) Blackcurrant (Ribes nigrum L.) —an insight into the crop. A synopsis of a Ph.D. study. Department of Plant Breeding and Biotechnology, Swedish University of Agricultural Sciences, Balsgård, Sweden, ISSN:16543580, p 58

Vieira RA, Scapim CA, Moterle LM, Tessmann DJ, Conrado TV, Amaral AT Jr. (2009) Diallel analysis of leaf disease resistance in inbred Brazilian popcorn cultivars. Genet Mol Res 8:1427-1436

Yao Q, Mehlenbacher SA (2000) Heritability, variance components and correlation of morphological and phenological traits in hazelnut. Plant Breed 119:369-381

Żurawicz E, Mądry W, Pluta S (1996) Variation and heritability of economically important traits in blackcurrant (Ribes nigrum L.) evaluated in a diallel cross design. Euphytica 91:219-224

Żurawicz E, Masny A, Mądry W (2006) Usefulness of selected strawberry (Fragaria $\times$ ananassa) genotypes for breeding late ripening cultivars. Acta Hortic 708:501-505 